Gynecologic and

Obstetric Investigation
Gynecol Obstet Invest 2011;72:130-134

DOI: $\underline{10.1159 / 000323542}$
Received: August 8, 2010

Accepted after revision: December 12, 2010

Published online: April 7, 2011

\title{
Melatonin Receptor 1A Gene Polymorphism Associated with Polycystic Ovary Syndrome
}

\author{
Chao Li ${ }^{a}$ Yuhua Shi ${ }^{b}$ Li You $^{c}$ Laicheng Wang ${ }^{c}$ Zi-Jiang Chen ${ }^{b}$ \\ aDepartment of Obstetrics and Gynecology, Affiliated Hospital of Medical College of Qingdao University, \\ Qingdao, and ${ }^{b}$ Shandong Provincial Key Laboratory of Reproductive Medicine, Center for Reproductive \\ Medicine, and ${ }^{\mathrm{C} C e n t r a l ~ L a b o r a t o r y, ~ P r o v i n c i a l ~ H o s p i t a l ~ A f f i l i a t e d ~ t o ~ S h a n d o n g ~ U n i v e r s i t y, ~ J i n a n, ~ C h i n a ~}$
}

\section{Key Words}

Melatonin receptor $1 \mathrm{~A} \cdot$ Polymorphism • Polycystic ovary syndrome

\begin{abstract}
Background/Aims: Melatonin receptor 1A (MTNR1A) gene is a regulator of circadian rhythms and reproductive processes. The MTNR1A gene is also a potential candidate gene of polycystic ovary syndrome (PCOS). The aim of the present study was to determine whether or not the MTNR1A gene polymorphism is associated with a predisposition to PCOS. Methods: The single nucleotide polymorphism (SNP) rs2119882 in the MTNR1A gene was detected in 482 patients with PCOS and 522 healthy Chinese Han women. Subsequently, the association of MTNR1A gene variants with plasma glucose, insulin levels during oral glucose tolerance tests (OGTTs) and hormone levels was investigated. Results: The frequencies of genotypes and allelotypes of SNP rs2119882 differed significantly between PCOS cases and healthy controls $(p<$ 0.001 and $p=0.002$, respectively). SNP rs 2119882 was associated with higher fasting plasma glucose concentrations $(\mathrm{p}=$ 0.021 ) and OGTT-induced insulin release at $0,30,60$, and 120 min (all $p<0.05$ ) in PCOS cases, as well as an increased homeostasis model assessment for insulin resistance ( $p=$ 0.005). Conclusion: SNP rs 2119882 is associated with PCOS.
\end{abstract}

\section{KARGER}

Fax +41613061234

E-Mail karger@karger.ch

www.karger.com
(C) 2011 S. Karger AG, Basel

0378-7346/11/0722-0130\$38.00/0

Accessible online at:

www.karger.com/goi

\section{Introduction}

Melatonin, the principal hormone of the pineal gland, is most widely recognized for its role in regulating mammalian circadian rhythms, sleep, and reproductive alterations [1-4]. There is increasing evidence that disturbances in circadian rhythmicity are closely linked to metabolic conditions, including diabetes and obesity, in humans and rodents $[5,6]$. In addition to controlling circadian rhythms, melatonin neutralizes reactive oxygen and nitrogen, and activates the immune system [7]. Reactive oxygen species and apoptosis are involved in a number of reproductive events, including folliculogenesis, follicular atresia, oocyte maturation, ovulation, and corpus luteum formation [2-4]. Thus, melatonin has direct effect on ovarian function. The function of melatonin is mainly mediated by melatonin receptor $1 \mathrm{~A}$ (MTNR1A) and $1 \mathrm{~B}$ (MTNR1B), both of which belong to the G-protein-coupled receptor superfamily. MTNR1A is mainly expressed in $\alpha$ cells, while MTNR1B is predominantly expressed in $\beta$ cells [8]. These findings suggest an important role of the MTNR1A and MTNR1B genes in the etiology and pathophysiology of polycystic ovary syndrome (PCOS). The link between MTNR1B gene polymorphisms and PCOS

\section{C.L. and Y.S. contributed equally to this work.}

Zi-Jiang Chen, MD, PhD

Shandong Provincial Key Laboratory of Reproductive Medicine, Center for Reproductive Medicine, Provincial Hospital Affiliated to Shandong University Jinan, Shandong 250021 (China)

Tel. +86 1325555 9046, E-Mail chenzijiang@ hotmail.com 
has been confirmed in a recent study [9]. However, there is no study on the relationship between the MTNR1A gene polymorphisms and PCOS.

The purpose of this study was to determine the relationship between the single nucleotide polymorphism (SNP) rs2119882, which is located at the promoter region in the MTNR1A gene, and the pathogenesis of PCOS. In addition, whether or not the MTNR1A gene plays a role in endocrine and clinical traits in PCOS patients, which may provide evidence for a better understanding of the susceptibility of the MTNR1A gene variation in the development of PCOS, was determined.

\section{Subjects and Methods}

\section{Subjects}

481 PCOS patients and 522 healthy residents of Shandong province were included in our study. All participants were northern Han ethnic women with complete clinical and biochemical data. PCOS was diagnosed by the Rotterdam PCOS consensus criteria [10]. The Rotterdam Criteria requires at least two of the following indicators for diagnosis of PCOS: oligomenorrhea or amenorrhea, clinical or biochemical signs of hyperandrogenism, and presence of PCOS, with the exclusion of other causes of hyperandrogenism such as hyperprolactinemia, androgen-secreting tumors, Cushing's syndrome and non-classical congenital adrenal hyperplasia. Everyone in the control group had normal ovulatory menstrual cycles and normal hormonal status. There was no hirsutism or other manifestations of hyperandrogenism, no sonographic signs of PCOS. No participants received hormonal therapy for at least 3 months before enrollment in the study. Informed consent had been obtained from all subjects. The study protocol was approved by the Ethics Committee of Shandong University. The clinical characteristics of the study subjects are shown in table 1 .

\section{Methods}

Blood samples were obtained on days $3-5$ of the menstrual cycles from the subjects in a fasting state for serum hormone detection. All PCOS patients had a $75 \mathrm{~g}$ oral glucose tolerance test (OGTT). Serum glucose and insulin levels were measured by enzymatic and chemiluminescent methods. The homeostasis model assessment for insulin resistance (HOMA-IR) was calculated according to the following equation: fasting glucose (FBG, $\mathrm{mmol} / \mathrm{l}) \times$ fasting insulin (FINS, $\mathrm{mU} / \mathrm{l}) / 22.5$. Follicle-stimulating hormone $(\mathrm{FSH})$, luteinizing hormone $(\mathrm{LH})$, prolactin (PRL), testosterone $(\mathrm{T})$, and estradiol $\left(\mathrm{E}_{2}\right)$ levels were measured by a chemiluminescent analyzer (Beckman Coulter Inc., Fullerton, Calif., USA). Total cholesterol (TC), triglycerides (TG), and low-density lipoprotein (LDL) concentrations were measured enzymatically on an automated biochemistry analyzer (Olympus 600, Clinical Chemistry Analyser; Olympus Diagnostica GmbH, Ireland).

Genomic DNA was isolated from human leukocytes using a DNA purification kit (Tiangen Biotech Co. Ltd, Beijing, China). Genotyping of the MTNR1A gene was performed with a polymerase chain reaction (PCR) Tm-shift genotyping method with
Table 1. Clinical characteristics of PCOS patients and normal healthy women (data represent mean \pm SD)

\begin{tabular}{lccrr}
\hline Characteristic & PCOS & Control & t & p value \\
\hline Number & 481 & 522 & & \\
Age, years & $29.11 \pm 3.64$ & $30.81 \pm 4.64$ & 6.314 & $<0.001$ \\
BMI & $24.99 \pm 3.97$ & $22.90 \pm 3.19$ & 8.673 & $<0.001$ \\
LH, MIU/ml & $10.96 \pm 7.36$ & $4.84 \pm 3.96$ & 14.392 & $<0.001$ \\
FSH, MIU/ml & $6.66 \pm 1.78$ & $9.28 \pm 9.27$ & 5.467 & $<0.001$ \\
PRL, ng/ml & $17.61 \pm 13.92$ & $19.60 \pm 23.09$ & 1.440 & 0.150 \\
T, ng/dl & $67.71 \pm 23.58$ & $49.11 \pm 24.56$ & 10.738 & $<0.001$ \\
E $_{2}, \mathrm{pg} / \mathrm{ml}$ & $52.97 \pm 32.37$ & $40.86 \pm 24.81$ & 5.775 & $<0.001$ \\
\hline
\end{tabular}

fluorescence melting curve analysis $[11,12]$. A common forward primer sequence is: rs2119882 $\mathrm{F}^{\prime}$ CTCTCTGGGATGGGACTTTTCACC; two reverse allele-specific primers with the $3^{\prime}$ base of each primer matching one of the allele bases of the SNP. The sequences of the reverse primers include rs2119882 C' GCGGGCAGGGCGGCCTAATCTCATTTCGCATTGGG and rs2119882 T' GCGGGCCTAATCTCATTTCGCATTGGA, differently. The PCR was performed as follows: 5 min preincubation at $95^{\circ} \mathrm{C}$ to activate the Taq DNA polymerase, followed by 35 cycles of denaturation at $95^{\circ} \mathrm{C}$ for $15 \mathrm{~s}$ and then primer annealing and extension for $34 \mathrm{~s}$ at $60^{\circ} \mathrm{C}$. The fluorescence melting curve was analyzed immediately following amplification. To validate the SNP genotyping assays, $5 \%$ of genotyped samples were randomly selected for duplication accuracy with a direct sequencing protocol (ABI 7300; Applied Biosystems, Foster City, Calif., USA) and the reproducibility was $100 \%$.

\section{Statistical Analysis}

The analysis was performed using the Statistical Package for the Social Sciences software (version 13.0; SPSS Inc., Chicago, Ill., USA). $p<0.05$ was accepted as statistically significant. The Hardy-Weinberg distribution of genotypes in the PCOS and control groups was assessed. The results of serum hormone levels were reported as the mean \pm SD. Categorical data were expressed as frequencies and percentages. Statistical analysis of allele and genotype frequencies between women with PCOS and controls was compared using Pearson's $\chi^{2}$ test. The differences among PCOS patients and controls in clinical and biochemical variables were evaluated by an independent samples t test. Differences in serum hormone levels among different genotypic individuals were assessed using the Mann-Whitney U test or one-way analysis of covariance in the PCOS group.

\section{Results}

The distributions of genotypes and allelic frequencies for the SNP rs2119882 are shown in table 2. No significant deviation of genotype frequencies from the Hardy-Weinberg equilibrium was found in the PCOS or control group (all $\mathrm{p}>0.05)$. 
Table 2. Genotype and allele frequencies of SNP rs2119882 in MTNR1A gene in PCOS with patients and healthy controls

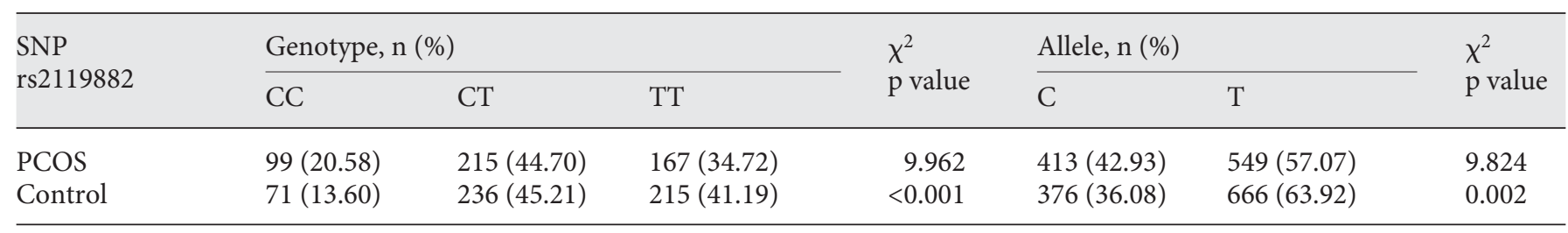

Table 3. Relationships between rs2119882 genotypes in MTNR1A gene and key phenotypic traits in PCOS patients

\begin{tabular}{|c|c|c|c|c|}
\hline Genotype & $\begin{array}{l}\mathrm{CT}+\mathrm{CC} \\
(\mathrm{n}=314)\end{array}$ & $\begin{array}{l}\mathrm{TT} \\
(\mathrm{n}=167)\end{array}$ & $\mathrm{t}$ & $\begin{array}{l}\mathrm{p} \\
\text { value }\end{array}$ \\
\hline Age, years & $29.22 \pm 3.65$ & $28.91 \pm 3.64$ & 0.816 & 0.415 \\
\hline $\mathrm{BMI}$ & $25.12 \pm 4.20$ & $24.58 \pm 4.06$ & 1.252 & 0.211 \\
\hline \multicolumn{5}{|l|}{ Glucose, $\mathrm{mmol} / \mathrm{l}$} \\
\hline \multicolumn{5}{|l|}{ OGTTs $0 \mathrm{~min}$} \\
\hline (fasting) & $5.03 \pm 1.12$ & $4.82 \pm 0.68$ & 2.314 & 0.021 \\
\hline OGTTs $30 \mathrm{~min}$ & $9.14 \pm 6.27$ & $8.86 \pm 3.42$ & 0.477 & 0.633 \\
\hline OGTTs $60 \mathrm{~min}$ & $9.72 \pm 12.74$ & $9.27 \pm 6.27$ & 0.391 & 0.696 \\
\hline OGTTs $120 \mathrm{~min}$ & $8.19 \pm 11.98$ & $7.61 \pm 6.93$ & 0.518 & 0.605 \\
\hline OGTTs $180 \mathrm{~min}$ & $6.22 \pm 14.41$ & $5.35 \pm 2.68$ & 0.701 & 0.484 \\
\hline \multicolumn{5}{|l|}{ Insulin, $m I U / l$} \\
\hline \multicolumn{5}{|l|}{ OGTTs $0 \mathrm{~min}$} \\
\hline (fasting) & $10.83 \pm 9.17$ & $8.57 \pm 5.39$ & 3.060 & 0.002 \\
\hline OGTTs $30 \mathrm{~min}$ & $72.93 \pm 47.36$ & $61.42 \pm 39.42$ & 2.406 & 0.017 \\
\hline OGTTs $60 \mathrm{~min}$ & $87.73 \pm 62.28$ & $72.07 \pm 44.97$ & 2.566 & 0.011 \\
\hline OGTTs $120 \mathrm{~min}$ & $75.98 \pm 75.24$ & $59.02 \pm 50.30$ & 2.353 & 0.019 \\
\hline OGTTs $180 \mathrm{~min}$ & $29.52 \pm 44.37$ & $24.17 \pm 26.45$ & 1.281 & 0.201 \\
\hline HOMA-IR & $2.47 \pm 0.48$ & $1.91 \pm 1.38$ & 2.854 & 0.005 \\
\hline $\mathrm{CHO}, \mathrm{mmol} / \mathrm{l}$ & $4.70 \pm 0.97$ & $4.58 \pm 0.92$ & 0.837 & 0.404 \\
\hline $\mathrm{TG}, \mathrm{mmol} / \mathrm{l}$ & $0.93 \pm 0.72$ & $0.92 \pm 0.56$ & 0.115 & 0.909 \\
\hline $\mathrm{LDL}, \mathrm{mmol} / \mathrm{l}$ & $3.07 \pm 1.08$ & $3.08 \pm 1.27$ & 0.040 & 0.968 \\
\hline $\mathrm{T}, \mathrm{ng} / \mathrm{dl}$ & $68.68 \pm 24.15$ & $65.97 \pm 22.52$ & 1.089 & 0.277 \\
\hline $\mathrm{E}_{2}, \mathrm{pg} / \mathrm{ml}$ & $51.59 \pm 25.44$ & $55.42 \pm 41.94$ & 0.968 & 0.334 \\
\hline $\mathrm{LH}, \mathrm{IU} / \mathrm{l}$ & $10.76 \pm 6.60$ & $11.32 \pm 8.55$ & 0.714 & 0.476 \\
\hline FSH, IU/l & $6.76 \pm 1.87$ & $6.46 \pm 1.60$ & 1.597 & 0.111 \\
\hline PRL, ng/ml & $17.27 \pm 10.37$ & $18.20 \pm 18.58$ & 0.631 & 0.529 \\
\hline
\end{tabular}

Data represent mean \pm SD. p value obtained by Mann-Whitney $U$ test or one-way analysis of variance.

The rs2119882 genotype frequencies of CC, CT, and TT were $13.60 \%$ (71/522), $45.21 \%$ (236/522), and $41.19 \%$ $(215 / 522)$ in the healthy controls, and $20.58 \%$ (99/481), $44.70 \%$ (215/481), and $34.72 \%$ (167/481) in the PCOS patients, respectively. The frequencies of the three genotypes did significantly differ between the PCOS patients and healthy controls $(\mathrm{p}<0.001)$. There were more carriers of the C allele in the PCOS group (42.93\% (413/962)) than the controls (36.08\% (376/1042), $\mathrm{p}=0.002)$. Furthermore, the PCOS patients with CC and CT genotypes had higher fasting plasma glucose and insulin levels at $0,30,60$, and 120 min during the OGTT compared with the patients with the TT genotype $(\mathrm{p}<0.05)$. Carriers of the CC and CT genotypes at rs2119882 also had increased HOMA-IR compared with the patients with the TT genotype in the PCOS patients $(\mathrm{p}=0.005)$.

There was no significant difference in age, BMI, and the levels of TC, TG, LDL, T, E , LH, FSH, and PRL in the different genotypes in PCOS patients (table 3).

\section{Discussion}

PCOS is a complex endocrine disease affecting 6-7\% of reproductive-aged women [13]. PCOS is characterized by oligomenorrhea or amenorrhea, hyperandrogenism, and multiple small subcapsular cystic follicles [14-16]. The disorder has also been reported to be associated with metabolic syndromes, such as T2DM, dyslipidemia, and hypertension $[17,18]$. The cause of PCOS is considered to be multifactorial and includes genetic, endocrine, and environmental factors. The increased risk of T2DM and cardiovascular disease in women with PCOS suggests that those affected might share same etiologic determinants, thus prompting an investigation between PCOS and T2DM-related genes [19, 20]. The MTNR1A and MTNR1B genes are two types of mammalian melatonin receptors. The MTNR1B gene is a novel candidate gene for T2DM. MTNR1A is vastly more abundant than MTNR1B; however, there have been no studies on the relationship between MTNR1A and PCOS, or on the etiology of the disorder. The MTNR1A gene is located at chromosome 4q35.1, and is composed of two exons that encode a protein of 350 amino acids. Morcuende et al. [21] demonstrated no evidence of linkage to chromosome $4 \mathrm{q}$ and no mutations in the coding region of the gene for the human melatonin receptor. The MTNR1A is likely to me- 
diate the two major biological functions of melatonin, and include circadian and reproductive effects in mammals [22].

A previous study showed that the aberrant variant in the promoter region of MTNR1A was inversely correlated with its expression in OSCC lines [23]. Furthermore, no mutation was detected in any of the coding exons (exons 1 and 2) of the MTNR1A gene in all of the cell lines tested, which proved that the promoter of the MTNR1A is a functional region and associated with MTNR1A expression [23]. SNP rs2119882 is located in the promoter region $(-369 \mathrm{bp})$ of the MTNR1A gene. According to HapMap [24], rs2119882 could capture the other two SNPs (rs11721818 and rs7687823) in the promoter region of the MTNR1A gene. The three SNPs covered $6.3 \mathrm{~kb}$ in the promoter region of the MTNR1A gene. Therefore, the SNP rs2119882 was the main functional SNP in MTNR1A. Consequently, rs2119882 was selected for the present study, and shown to be associated with an increased risk of PCOS. The distributions of the genotypes and allelic frequencies of rs2119882 were significantly different between the PCOS patients and controls. The PCOS patients had a significantly increased frequency of the $\mathrm{C}$ allele in comparison with the controls, which indicated that rs2119882 does affect the etiology of PCOS.

A previous study confirmed that there are high concentrations of melatonin in the serum and lower melatonin concentrations in the ovarian follicles of women with PCOS [25]. Another study also indicated that administration of melatonin to ewes decreases the atresia rate of large follicles and increases the ovulation rate and embryo viability [26]. These studies indicated that abnormal melatonin is an important change in PCOS patients. Forcada et al. [27] found that the SNP of MTNR1A was linked to the magnitude of the ovulation rate. Therefore, the abnormal variant of SNP rs2119882 could lead to function and activity changes of melatonin, and accordingly may contribute to the etiopathogenesis of PCOS.

Our study also showed that with respect to the SNP rs2119882 in the MTNR1A gene, the PCOS cases carrying genotypes CC and CT had significantly increased fasting glucose levels and insulin release during the OGTT compared with the patients with genotype TT. The CC and CT genotypes are significantly associated with increased HOMA-IR in PCOS patients. The MTNR1A gene is coupled to an inhibitory G protein, which inactivates adenylate cyclase and lowers the cAMP levels in $\beta$ cells, which could result in an elevated fasting plasma glucose level [28]. The MTNR1A gene is also coupled to Gq, which activates PLC, thus cleaving phospha- tidylinositol-4,5-biphosphate $\left(\mathrm{PIP}_{2}\right)$ into inositol-1,4,5triphosphate $\left(\mathrm{IP}_{3}\right)$ and diacylglycerol (DAG), and the $\mathrm{IP}_{3}$ stimulates calcium release from the endoplasmic reticulum. This signaling pathway has an enhancing effect on insulin secretion [29].

Our study provides further insight into the mechanism of insulin resistance in patients with PCOS. Variants in rs2119882 may result in quantitative or qualitative changes in MTNRA activity, thus influencing melatonin signaling and perhaps ultimately affecting glucose homeostasis and insulin release.

This is the first report demonstrating that the SNP rs2119882 is one of the key factors responsible for the etiopathogenisis of PCOS among Han Chinese women. The strong association between SNP rs2119882 of the MTNR1A gene and fasting glucose and insulin release and HOMA-IR indicate that SNP rs2119882 contributes to the phenotypic characteristics of PCOS, suggesting that SNP rs2119882 may play a common causative role in the pathogenesis of PCOS. PCOS is considered a polygenic trait that might result from the interaction of susceptible and protective gene variants under the influence of environmental factors. Current genetic studies have failed to identify a specific gene or genes with clear clinical significance. In order to apply the present findings clinically, further studies are required to achieve functional evaluation of MTNR1A as well as the interaction with other gene polymorphisms in patients with PCOS.

\section{Acknowledgements}

We thank all participants who made this work possible and gratefully acknowledge the support of the clinicians and researchers who contributed towards this study. This work was supported by the National Basic Research Program of China (973 Program.2007CB948103).

References $\quad$ J Jaworek J, Nawrot-Porabka K, Leja-Szpak A, Bonior J, Szklarczyk J, Kot M, Konturek SJ, Pawlik WW: Melatonin as modulator of pancreatic enzyme secretion and pancreatoprotector. J Physiol Pharmacol 2007;58(suppl 6):65-80.

$\checkmark 2$ Woo MM, Tai CJ, Kang SK, Nathwani PS, Pang SF, Leung PC: Direct action of melatonin in human granulosa-luteal cells. J Clin Endocrinol Metab 2001;86:4789-4797.

-3 Adriaens I, Jacquet P, Cortvrindt R, Janssen $\mathrm{K}$, Smitz J: Melatonin has dose-dependent effects on folliculogenesis, oocyte maturation capacity and steroidogenesis. Toxicology 2006;228:333-343. 
$>_{4}$ Voordouw BC, Euser R, Verdonk RE, Alberda BT, de Jong FH, Drogendijk AC, Fauser BC, Cohen M: Melatonin and melatoninprogestin combinations alter pituitary-ovarian function in women and can inhibit ovulation. J Clin Endocrinol Metab 1992;74: 108-117.

5 Spiegel K, Leproult R, Van CE: Impact of sleep debt on metabolic and endocrine function. Lancet 1999;354:1435-1439.

-6 Turek FW, Joshu C, Kohsaka A, Lin E, Ivanova G, McDearmon E, Laposky A, LoseeOlson S, Easton A, Jensen DR, Eckel RH, Takahashi JS, Bass J: Obesity and metabolic syndrome in circadian Clock mutant mice. Science 2005;308:1043-1045.

-7 Jaworek J, Nawrot-Porabka K, Leja-Szpak A, Bonior J, Szklarczyk J, Kot M, Konturek SJ, Pawlik WW: Melatonin as modulator of pancreatic enzyme secretion and pancreatoprotector. J Physiol Pharmacol 2007;58(suppl 6):65-80

8 Staiger H, Machicao F, Schafer SA, Kirchhoff K, Kantartzis K, Guthoff M, Silbernagel G, Stefan N, Haring H-U, Fritsche A: Polymorphisms within the novel type 2 diabetes risk locus MTNR1B determine $\beta$-cell function. PLoS One 2008;3:3962-3970.

-9 Wang L, Wang Y, Zhang X, Shi J, Wang M, Wei Z, Zhao A, Li B, Zhao X, Xing Q, He L: Common genetic variation in MTNR1B is associated with serum testosterone, glucose tolerance, and insulin secretion in polycystic ovary syndrome patients. Fertil Steril 2010; 94:2486-2489.

10 The Rotterdam ESHRE/ASRM-sponsored PCOS Consensus Workshop Group: Revised 2003 consensus on diagnostic criteria and long-term health risks related to polycystic ovary syndrome. Hum Reprod 2004;19:4147.

11 Papp AC, Pinsonneault JK, Cooke G, Sadée W: Single nucleotide polymorphism genotyping using allele-specific PCR and fluorescence melting curves. Biotechniques 2003; 34:1068-1072.
12 Wang J, Chuang K, Ahluwalia M, Pate S, Umblas N, Mire D, Higuch R, Germer S: High-throughput SNP genotyping by singletube PCR with Tm-shift primers. Biotechniques 2005;39:885-893.

13 Franks S: Polycystic ovary syndrome in adolescents. Int J Obes 2008;32:1035-1041.

14 Apridonidze T, Essah PA, Iuorno MJ, Nestler JE: Prevalence and characteristics of the metabolic syndrome in women with polycystic ovary syndrome. J Clin Endocrinol Metab 2005;90:1929-1235.

15 Franks S, Gharani N, Waterworth D, Batty S, White D, Williamson R, McCarthy M: Genetics of polycystic ovary syndrome. Mol Cell Endocrinol 1998;145:123-128.

16 Sheehan MT: Polycystic ovarian syndrome: diagnosis and management. Clin Med Res 2004;2:13-27.

17 Ehrmann DA, Liljenguist DR, Kasza K, Azziz R, Legro RS, Ghazzi MN (PCOS/Troglitazone Study Group): Prevalence and predictors of the metabolic syndrome in women with polycysticovary syndrome. J Clin Endocrinol Metab 2006;91:48-53.

18 Carey AH, Waterworth D, Patel K, White D, Little J, Novelli P, Franks S, Williamson R: Polycystic ovaries and premature male pattern baldness are associated with one allele of the steroid metabolism gene CYP17. Hum Mol Genet 1994;3:1873-1876.

19 Valdés P, Cerda A, Barrenechea C, Kehr M, Soto C, Salazar LA: No association between common Gly972Arg variant of the insulin receptor substrate-1 and polycystic ovary syndrome in Southern Chilean women. Clin Chim Acta 2008;390:63-66.

20 Simoni M, Tempfer CB, Destenaves B, Fauser BC: Functional genetic polymorphisms and female reproductive disorders. I. Polycystic ovary syndrome and ovarian response. Hum Reprod Update 2008;14:459-484.
21 Morcuende JA, Minhas R, Dolan L, Stevens J, Beck J, Wang K, Weinstein SL, Sheffield V: Allelic variants of human melatonin $1 \mathrm{~A}$ receptor in patients with familial adolescent idiopathic scoliosis. Spine 2003;28:20252029.

-22 Slaugenhuaupt SA, Roca AL, Liebert CB Altherr MR, Gnsella JF, Reppert SM: Mapping of the gene for the MEL1A-melatonin receptor to human chromosome 4 (MTNR1A) and mouse chromosome 8 (Mtnrla). Genomics 1995;27:355-357.

23 Nakamura E, Kozaki K, Tsuda H, Suzuki E, Pimkhaokham A, Yamamoto $G$, Irie $T$, Tachikawa T, Amagasa T, Inazawa J, Imoto I: Frequent silencing of a putative tumor suppressor gene melatonin receptor $1 \mathrm{~A}(\mathrm{MTN}$ R1A) in oral squamous cell carcinoma. Cancer Sci 2008;99:1390-1400.

24 The International HapMap Consortium. The International HapMap Project. Nature 2003;426:789-796.

25 Tamura H, Nakamura Y, Korkmaz A, Manchester LC, Tan DX, Sugino N, Reiter RJ: Melatonin and the ovary: physiological and pathophysiological implications. Fertil Steril 2009;92:328-343.

26 Bister JL, Noël B, Perrad B, Mandiki SN, Mbayahaga J, Paquay R: Control of ovarian follicle activity in the ewe. Domest Anim Endocrinol 1999;17:315-328.

-27 Forcada F, Abecia J, Cebrián-Pérez J, MuiñoBlanco T, Valares J, Palacín I, Casao, A: The effect of melatonin implants during the seasonal anestrus on embryo production after superovulation in aged high-prolificacy rasa aragonesa ewes. Theriogenology 2006; 65: 356-365.

28 Von Gall C, Stehle JH, Weaver DR: Mammalian melatonin receptors: molecular biology and signal transduction. Cell Tissue Res 2002;309:151-162.

29 Godson C, Reppert SM: The Mella melatonin receptor is coupled to parallel signal transduction pathways. Endocrinology 1997;138:397-404 